\title{
Tandem Affinity Purification and Nano HPLC-ESI-MS/MS Reveal Binding of Vitamin D Receptor to p53 and other New Interaction Partners in HEK 293T Cells
}

\author{
ANJA PEMSEL ${ }^{1,2}$, SASKIA RUMPF $^{1,2}$, KLAUS ROEMER $^{2}$, KRISTINA HEYNE $^{1}$, \\ THOMAS VOGT ${ }^{1}$ and JOERG REICHRATH ${ }^{1}$ \\ ${ }^{1}$ Department of Dermatology, The Saarland University Hospital, Homburg, Germany; \\ ${ }^{2}$ José Carreras Center and Internal Medicine I, University of Saarland Medical Center, Homburg, Germany
}

\begin{abstract}
While nuclear cofactors that contribute to vitamin $D$ receptor (VDR)-mediated gene transcription, including retinoid $X$ receptors, nuclear co-activators and co-repressors, have been extensively investigated, little is known about cytoplasmic VDR-binding partners and the physiological relevance of their interaction. To gain new insight into this topic, we isolated whole-cell protein extracts of 1,25dihydroxyvitamin $D_{3}$ stimulated and UV-B-irradiated vs. nonirradiated HEK 293 cells transfected with a plasmid called pURB VDR C-Term TAP tag. VDR complex was purified by tandem affinity purification (TAP). The nuclear tumorsuppressor protein p53 and its negative regulator novel INHAT repressor (NIR), in addition to 43 other nuclear or cytoplasmatic VDR binding partners, were identified using nano high-performance liquid chromatography-electrospray ionization tandem mass spectrometric analysis. VDR binding to 553 was confirmed by western blot analysis. Future studies are required to further elucidate the functional significance of these interactions.
\end{abstract}

The vitamin $\mathrm{D}$ endocrine system is of great importance for human health (1). The biological effects of 1,25dihydroxyvitamin $\mathrm{D}_{3}\left(1,25-\mathrm{D}_{3}\right)$, the biologically most active natural vitamin $\mathrm{D}$ metabolite, are at least in part mediated via binding to a corresponding high affinity nuclear receptor protein, the vitamin D receptor (VDR) $(1,2)$. VDR belongs to the family of nuclear transcription factors. After ligand binding, conformational changes induce heterodimerization

This article is freely accessible online.

Correspondence to: Joerg Reichrath, Department of Dermatology, The Saarland University Hospital, Kirrberger Straße, 66421 Homburg, Germany. Tel: +49 68411623802, e-mail: joerg.reichrath@uks.eu

Key Words: Vitamin D, Vitamin D receptor, tandem affinity purification. of VDR with retinoid $X$ receptor (RXR) and modulate binding of nuclear co-receptor proteins. In general, binding of nuclear co-activator proteins (NCoAs) is induced, while binding of co-repressor proteins is reduced, enabling the binding of this receptor complex to vitamin $\mathrm{D}$ responsive elements in the promoter region of target genes.

Consequently, the biological effects of vitamin D compounds in an individual cell strongly depend upon the presence of the ligand at sufficient concentrations and the adequate expression of VDR, RXR and co-receptor proteins (3).

While nuclear cofactors that contribute to VDR-mediated gene transcription, have been investigated extensively, little is known about cytoplasmic and membrane VDR-binding partners and the physiological relevance of their interaction. Interestingly, binding of VDR has been shown to endoplasmatic reticulum stress protein 57 (ERp57) that is of importance for the photoprotective effects of vitamin D compounds (4). To gain new insight into nuclear and cytoplasmic interaction partners of VDR, we aimed to isolate whole-cell protein extracts of $1,25-\mathrm{D}_{3}$ stimulated and UV-B-irradiated $v s$. non-irradiated HEK 293T cells transfected with a plasmid called pURB VDR C Term TAP tag and to identify VDR complexes by tandem affinity purification (TAP) and nano high-performance liquid chromatography-electrospray ionization tandem mass spectrometric (HPLC-ESI-MS/MS) analysis.

\section{Materials and Methods}

Plasmids, chemicals and antibodies. pURB C Term TAP tag plasmid was kindly provided by Roland Schüle (Department of Urology, Central Clinical Research, University Clinic Freiburg, Medical Faculty, Albert Ludwig University Freiburg, Freiburg, Germany). pURB C Term TAP tag containing VDR cDNA (pURB $\mathrm{C}$ Term TAP tag VDR) was generated by polymerase chain reaction (PCR). Cloning details are available upon request.

The antibody to p53, DO-1, was purchased from Merck (Darmstadt, Germany). 1,25- $\mathrm{D}_{3}$, protease inhibitor cocktail, AC-15 
monoclonal antibody to $\beta$-actin, anti-Flag antibody $\mathrm{M} 2$ and peroxidase-conjugated secondary anti-mouse antibody were from Sigma-Aldrich (Taufkirchen, Germany). Anti-VDR antibody 9A7 was from Abcam (Cambridge, UK).

Cell culture, transfection and treatment of cells with 1,25-D $D_{3}$ and UVB. HEK 293T cells were maintained at $37^{\circ} \mathrm{C}$ in an atmosphere with $7 \%$ $\mathrm{CO}_{2}$ and cultivated in Dulbecco's modified Eagle's medium (PAA, Pasching, Austria) with $10 \%$ fetal calf serum (PAA). For transient transfection, cells were seeded to reach $60-70 \%$ confluency at day of transfection and were transfected with jetPEI (Polyplus, Illkirch, France) following the manufacturer's recommendations. To gain new insights into the potential functional relevance of VDR-binding partners for the photoprotective activity of VDR, subpopulations of cells were treated with $1,25-\mathrm{D}_{3}$ at $10^{-7} \mathrm{M}$ with/without UVB at 100 $\mathrm{J} / \mathrm{cm}^{2}$ using a UVB lamp (Waldmann, Villingen, Germany).

Tandem affinity purification. Tandem affinity purification was fundamentally carried out as described $(5 ; 6)$ with the following variations. HEK $293 \mathrm{~T}$ cells $\left(8 \times 10^{7}\right)$ were seeded and $24 \mathrm{~h}$ later transfected with pURB C Term TAP tag VDR and pURB C Term TAP tag respectively using JetPEI. After 20 hours, cells were treated with 100 $\mathrm{nM} 1,25-\mathrm{D}_{3}$. Four hours after $1,25-\mathrm{D}_{3}$ treatment, one half of the cells were irradiated with $100 \mathrm{~J} / \mathrm{cm}^{2} \mathrm{UVB}$, whereas the other half was mocktreated. Another $4 \mathrm{~h}$ later, the cells were harvested and lysed by repeated freeze-thaw cycles in buffer $\mathrm{A}(420 \mathrm{mM} \mathrm{NaCl} ; 20 \mathrm{mM} \mathrm{HEPES} / \mathrm{KOH}$ at pH 7.9; $10 \mathrm{mM} \mathrm{KCl} ; 1.5 \mathrm{mM} \mathrm{MgCl} 2 ; 0.1$ mM EDTA; $50 \mathrm{mM} \mathrm{NaF} ; 0.2$ $\mathrm{mM} \mathrm{Na} \mathrm{VO}_{4} ; 25 \%$ glycerol; $0.1 \% \mathrm{NP}-40 ; 0.5 \mathrm{mM}$ dithiothreitol (DTT) and protease inhibitor cocktail). TAP-tagged proteins were coupled to IgG Sepharose ${ }^{\mathrm{TM}} 6$ Fast Flow (GE Healthcare, Little Chalfont, UK) in salt-adjusted buffer $\mathrm{A}(150 \mathrm{mM} \mathrm{NaCl})$ at $4^{\circ} \mathrm{C}$ overnight followed by repeated washing. TAP-VDR-containing complexes were released with TEV-protease (100 U; Invitrogen, Carlsbad, CA, USA) in TEV buffer (10 mM Tris/HCl at $\mathrm{pH} 8.0 ; 150 \mathrm{mM} \mathrm{NaCl} ; 0.1 \% \mathrm{NP}-40 ; 1 \mathrm{mM}$ DTT; $1 \mathrm{mM}$ EDTA) at $4^{\circ} \mathrm{C}$ overnight. Complexes containing TAP-tagged VDR were bound to a calmodulin affinity resin (Agilent Technologies, Santa Clara, CA, USA) for $4 \mathrm{~h}$ at $16^{\circ} \mathrm{C}$, following an overnight incubation at $4^{\circ} \mathrm{C}$. After five washing steps of the complexes with calmodulin-binding peptide (CBP) buffer (CBB) $(10 \mathrm{mM}$ Tris/ $\mathrm{HCl}$ at pH 8.0; $150 \mathrm{mM} \mathrm{NaCl} ; 0.1 \%$ NP-40; $1 \mathrm{mM} \mathrm{Mg-acetate;} 1 \mathrm{mM}$ imidazole; $10 \mathrm{mM} \beta$-mercaptoethanol; $2 \mathrm{mM} \mathrm{CaCl}_{2}$ ), they were finally eluted at $4^{\circ} \mathrm{C}$ for $24 \mathrm{~h}$ with CBB containing $10 \mathrm{mM}$ EGTA instead of $\mathrm{CaCl}_{2}$ (called CEB). Two percent of this first eluate was saved for later western blot analysis. In a second elution, calmodulin affinity resin was incubated with CEB for $4 \mathrm{~h}$ at $4^{\circ} \mathrm{C}$. Eluates from the first and second elution were pooled and concentrated via trichloroacetic acid (TCA) precipitation.

TCA precipitation. Eluates were adjusted to $25 \%$ TCA with $100 \%$ TCA and incubated on ice for 30 minutes (or overnight at $-20^{\circ} \mathrm{C}$ ) with periodic vortexing. After centrifugation at $16,100 \times g$ at $4^{\circ} \mathrm{C}$ for 10 minutes, pellets were washed in $-20^{\circ} \mathrm{C}$ acetone containing $0.05 \mathrm{~N} \mathrm{HCl}$ following a further centrifugation step $(16,100 \times g)$ at $4^{\circ} \mathrm{C}$ for 5 minutes. After washing with $-20^{\circ} \mathrm{C}$ acetone, proteins were pelleted by centrifugation at maximum speed for $5 \mathrm{~min}$ at $4^{\circ} \mathrm{C}$. Pellets were dried at $37^{\circ} \mathrm{C}$ overnight and then re-solved in $15 \mu \mathrm{l} \mathrm{CEB}$.

Sodium dodecyl sulfate polyacrylamide gel electrophoresis (SDS$P A G E)$ and silver staining. Resolved proteins were mixed 1:1 in SDSlysis buffer (100 mM Tris-HCl (pH 6.8), 100 mM DTT, 4\% SDS, and
$20 \%$ glycerol) heated to $100^{\circ} \mathrm{C}$ and incubated for 10 minutes at $100^{\circ} \mathrm{C}$. The denatured eluate was size-separated by $10 \%$ SDS-PAGE and visualized by silver gel staining using FireSilver StainingKit (Proteome Factory AG, Berlin, Germany), according to the manufacturer's protocol. Silver-stained protein bands were cut out and proteins identified by NanoHPLC-ESI-MS/MS (Proteome Factory AG).

NanoHPLC-ESI-MS/MS. Protein identification was performed by Proteome Factory AG (Berlin, Germany). Protein spots were in-gel digested by trypsin (Promega, Mannheim, Germany) (7) and analyzed by nanoHPLC-ESI-MS/MS. The LC-MS system consisted of an Agilent 1100 nanoHPLC system (Agilent, Waldbronn, Germany), PicoTip electrospray emitter (New Objective, Woburn, MA, USA) and an Orbitrap XL or LTQFT Ultra mass spectrometer (ThermoFisher Scientific, Bremen, Germany). Peptides were first trapped and desalted on an enrichment column (Zorbax 300SB-C18, 0.3 $\times 5 \mathrm{~mm}$; Agilent) for 5 minutes (solvent: $2.5 \%$ acetonitrile/ $0.5 \%$ formic acid), then separated on a Zorbax 300SB-C18 column $(75 \mu \mathrm{m} \times 150 \mathrm{~mm}$; Agilent $)$ using a linear gradient from $10 \%$ to $32 \% \mathrm{~B}$ (solvent A: $5 \%$ acetonitrile in water, with $0.1 \%$ formic acid; solvent $\mathrm{B}$ : acetonitrile with $0.1 \%$ formic acid). Ions of interest were data-dependently subjected to MS/MS according to the expected charge state distribution of peptide ions. Proteins were identified by database search against the National Center for Biotechnology Information (NCBI) protein database (NCBI, Bethesda, MD, USA) using MS/MS ion search of the Mascot search engine (8). Only peptides matches with a score of 100 or above were accepted and are shown in Table I. The peptide score in mass spectrometry is a nondimensional value that shows the dimension of conformity of predicted fragment spectrums of calculated, mass-matching peptides.

Western blot analysis. Two percent of the first TAP eluate was mixed 1:1 in SDS-lysis buffer heated to $100^{\circ} \mathrm{C}$ and incubated for $10 \mathrm{~min}$ at $100^{\circ} \mathrm{C}$. The denatured proteins were subjected to $10 \%$ SDS-PAGE and transferred to a polyvinylidene difluoride membrane (Immobilon-P; Merck Millipore, Burlington, MA, USA). Signals were detected upon overnight incubation of the membrane with the p53 antibody DO-1 (1:2,000), followed by a final incubation with a peroxidase-conjugated secondary anti-mouse $(1: 2,000)$ antibody, and detected by Thermo Scientific ECL Western Blotting substrate (Thermo Scientific, Rockford, IL, USA) as specified by the supplier.

\section{Results and Discussion}

It was the aim of this pilot study to gain new insights into the molecular mechanisms that mediate vitamin D signaling by identifying new VDR-binding partners. Because standard techniques to detect VDR interaction partners are characterized by limitations that include low VDR protein expression and cross-reactivity of VDR antibodies with other proteins, we have established a new approach, using TAP (5) and nano-HPLC-ESIMS/MS (9) for the first time to identify new VDR-binding partners in whole-cell extracts of $1,25-\mathrm{D}_{3}$-treated/UVB-irradiated versus $1,25-\mathrm{D}_{3}$-treated/non-irradiated HEK $293 \mathrm{~T}$ cells.

Since we were particularly interested in the photoprotective role of VDR, we intended to identify nuclear, cytoplasmic and mitochondrial VDR-binding partners in $1,25-\mathrm{D}_{3}$-treated/UVB-irradiated/non-irradiated 
Table I. Identification of 45 nuclear or cytoplasmic vitamin D receptor (VDR)-binding proteins in 1,25-dihydroxyvitamin $D_{3}\left(1,25\right.$ - $\left.D_{3}\right)$-treated HEK 2937 cells (mass spectrometry, score of 100 or above).

\section{Proteins detected in:}

UV-B-treated samples

Mock-treated samples (no UV-B)

40S Ribosomal protein S2 40S Ribosomal protein S3a 40S Ribosomal protein S6 60S Ribosomal protein L3 60S Ribosomal protein L7 Brain myo-inositol monophosphatase A2b Double-strand break repair protein MRE11A

Immunoglobulin gamma heavy chain variable region Immunoglobulin lambda light chain variable region Interleukin-17 receptor $\mathrm{C}$ MRPS27 protein

RNA polymerase-associated protein RTF1 ruvB-like 2
UV-B and mock-treated samples:

28S Ribosomal protein S22

40S Ribosomal protein S3

40S Ribosomal protein S4

40S Ribosomal protein SA

60S Acidic ribosomal protein $\mathrm{P} 0$

60S Ribosomal protein L5

ADP/ATP translocase 2

ADP/ATP translocase 3

Cellular tumor antigen $\mathrm{p} 53$

Coatomer subunit alpha

ELAV-like protein 1

Heterogeneous nuclear ribonucleoproteins $\mathrm{C} 1 / \mathrm{C} 2$

Myosin light chain kinase 2

Nucleolar complex protein 2

Nucleolin

Nucleophosmin

Polyadenylate-binding protein 1

Serine/arginine-rich splicing factor 1

Tubulin beta chain

Vimentin
HEK 293T cells. Figure 1 shows the scheme of the TAP strategy, which, in combination with nanoHPLC-ESIMS/MS, enables the identification of proteins associating with a given target under native conditions, in our case VDR.

Transfection of HEK 293T cells with a pURB C Term TAP tag vector in which VDR cDNA was inserted and which contained a fusion cassette encoding CBP, a Tobacco Etch Virus (TEV) cleavage site, as well as protein A of Staphylococcus aureus (Figure 2) resulted in strong expression of TAP-tagged VDR (lane 1 Figure 3a). Figure 3a shows our step-by-step analysis of the eluates of the TAP-VDR purification. Whole cell extract (lane 1 Figure 3a) and a fraction of each eluate was subjected to SDS-PAGE, followed by detection of TAP-VDR by western blot using VDR antibody (9A7). The successfully TAP-isolated and TCA-concentrated eluates (lane 5, Figure 3a) were utilized for size separation by SDS-PAGE, followed by silver staining to visualize the bands which represented VDR-associated proteins (Figure 3b).

Protein spots were cut out and submitted to nanoHPLCESI-MS/MS. TAP-VDR-associated proteins were identified by search against the NCBI protein database. Only peptide matches with a score of 100 or above were accepted and are shown in Table I. The MS analysis revealed (direct or indirect) binding of VDR to at least 45 nuclear, mitochondrial or cytoplasmic proteins (Table I).
While nuclear cofactors that contribute to VDR-mediated gene transcription, including RXRs, NCoAs and corepressors, have been investigated extensively, little is known about cytoplasmic or mitochondrial VDR-binding partners and the physiological relevance of these interactions. Interestingly, in this pilot study, we were able to identify new potential nuclear [e.g. p53, novel INHAT repressor (NIR)], cytoplasmic (e.g. tubulin $\beta$ chain, vimentin), mitochondrial (e.g. heat-shock protein 60 (HSP60), mitochondrial ribosomal protein S27 (MRPS27), ADP/ATP translocase 2 and 3) and ribosomal (40S ribosomal protein S2, S6, L7) VDR-interacting proteins, indicating that VDR may exert, beside its well-known function as a nuclear transcription factor, other important biological mechanisms that include effects on cytoplasmic, mitochondrial and ribosomal cell compartments.

Interestingly, our nanoHPLC-ESI-MS/MS analysis identified several nuclear VDR-binding proteins whose main function is related to regulation of gene transcription (e.g. mediator of RNA polymerase II, general transcription factor IIF, NIR), DNA repair (e.g. double-strand break repair protein MRE11A, ruvB-like 2) and cell fate decision (e.g. p53, NIR).

Using nanoHPLC-ESI-MS/MS, we detected an association between VDR and the tumor-suppressor protein p53 in both 
UVB-irradiated and non-irradiated cells (Table I). The interaction of VDR and p53 was confirmed in western blot analysis of TAP-isolated and TCA-concentrated eluate (lane 5 Figure 3a) using an antibody directed against p53 (lane 1 and 2, Figure 4). In HEK 293 T cells transfected with the empty control vector pURB C Term TAP tag, no p53 was precipitated (lane 3 and 4, Figure 4), indicating specific binding of VDR and p53. It can be speculated whether both proteins bind directly to each other or whether a third protein is involved which bridges both transcription factors. HEK 293T cells have been shown to contain wild-type p53 protein (10), a key regulator of cell fate decisions including cell-cycle arrest and apoptosis. This central stress response protein is activated by numerous endogenous and environmental stressors, including UV radiation. In skin, p53 is essential for protection against UV-induced DNA damage, and loss of its function promotes UV-induced skin tumorigenesis (11-13). It has been shown that UV radiation blocks gene transcription and induces nucleolar disruption, which in turn results in p53 accumulation. If the stalling of the transcription machinery persists, p53 protein accumulates further and cell-cycle arrest or apoptosis are induced. Interestingly, both VDR and p53 have been described as tumor suppressors in skin $(14,15)$. Activity of both, p53 and VDR, is influenced by modifications, localization, and protein-protein interactions that modulate transcription of genes. Our finding of VDR binding to p53 further lends credence to our suggestion of a crosstalk between these signaling pathways. Remarkably, interaction of VDR with mutated p53 protein, and the relevance of this finding for carcinogenesis have been reported previously. Stambolsky and co-workers showed that mutant p53 (mutation in sequence specific DNA-binding domain at position 175) interacts functionally and physically with VDR. They showed that mutant p53 is recruited to VDR-responsive genes and modifies their expression (overexpression or repression of some genes). Moreover, mutant $\mathrm{p} 53$ is able to convert $1,25-\mathrm{D}_{3}$ from a pro- to an antiapoptotic agent (16). Whether VDR and wild-type p53 influence each other concerning their capability to transactivate gene transcription and to what extent the ligand $1,25-\mathrm{D}_{3}$ interferes with this association are interesting questions that need to be addressed in further experiments. Considering the high physiological relevance of wild-type p53 as major barrier to cancer progression, our new finding will encourage future studies to elucidate the significance of the association of both proteins.

Remarkably, our study identified new nuclear VDRbinding partners that control p53-mediated biological effects, including the novel inhibitor of histone acetyl transferases (INHAT) repressor NIR, which modulates the transcriptional activity of p53 and of its relative p63 $(6,17,18)$ as well as nuclease-sensitive element-binding protein 1 (19), ELAV-like protein 1 (20-22) and nucleophosmin (23).
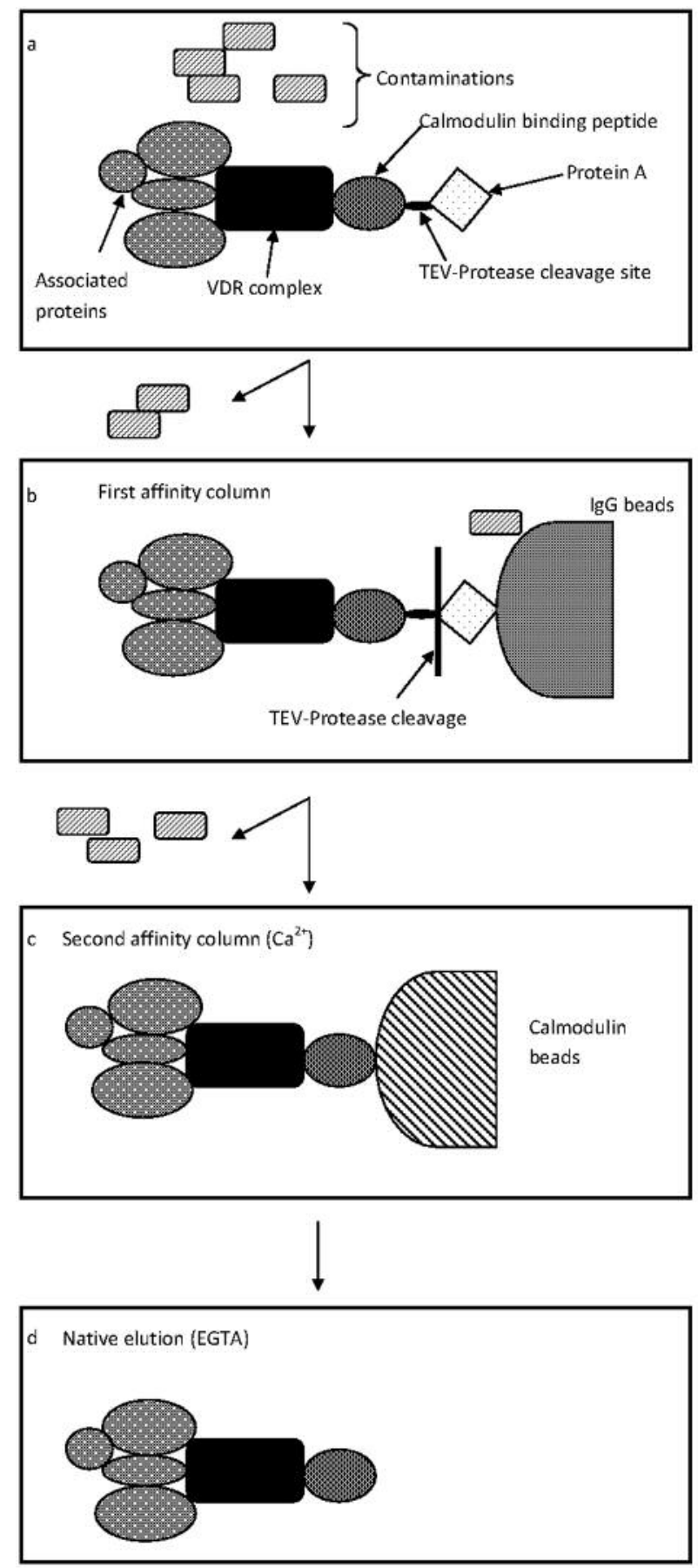

Figure 1. Scheme of the tandem affinity purification (TAP) strategy. a: Fusion protein, consisting of vitamin D receptor (VDR), calmodulinbinding peptide, Tobacco Etch Virus (TEV) protease cleavage site and protein A, and associated proteins. $b$ : VDR and interacting components are recovered from cell extracts by first affinity column on an IgG matrix. After several washing steps to remove unbound contaminants, complexes were incubated with TEV protease to release the bound material. c: In a second affinity step, calmodulin-coated beads are added to the eluate to remove the TEV protease and further contaminants. $d$ : Bound complexes were released in the presence of EGTA after washing several times. 


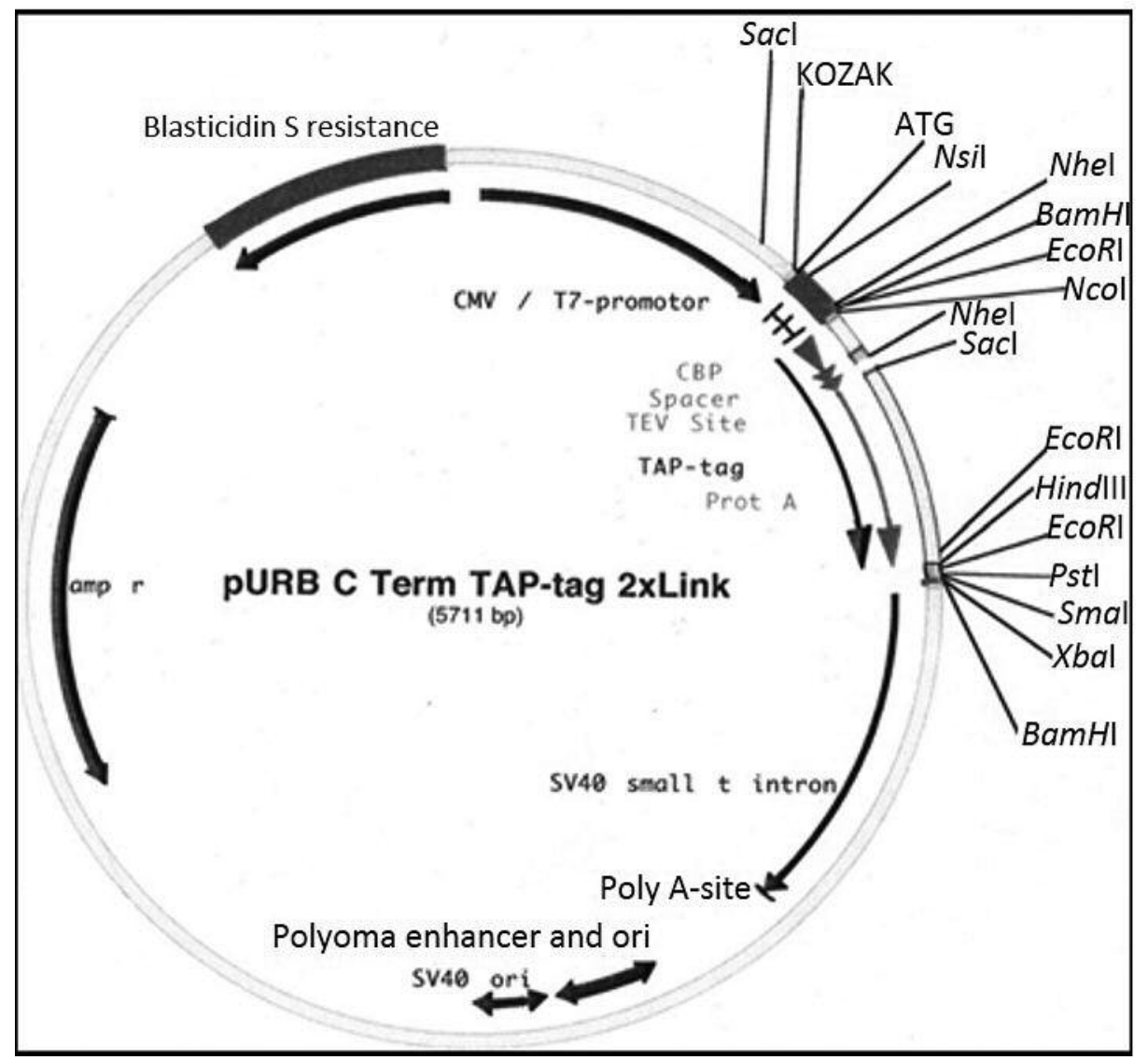

Figure 2. Plasmid pURB C Term TAP-tag containing a fusion cassette encoding calmodulin-binding peptide (CBP), a Tobacco Etch Virus (TEV) cleavage site as well as protein A of Staphylococcus aureus (ProtA) used for the tandem affinity purification (TAP); vitamin D receptor (VDR) cDNA was generated by polymerase chain reaction and subcloned into this vector to identify VDR-interacting proteins. amp r: Ampicillin resistance; CMV: cytomegalovirus; Poly A-site: polyadenylation site; ori: origin of replication.

Our MS data that indicate VDR binding to nuclear located mediator of RNA polymerase II (Table I) are in line with the results of Rachez and coworkers. They showed that immobilized glutathione-S-transferase (GST)-VDR, incubated with nuclear extracts of human Burkitt lymphoma cell line Namalwa, stably interact with subunits of the mediator of RNA-polymerase II complex in the presence of $1,25-\mathrm{D}_{3}(24)$. The recruitment of the mediator of RNApolymerase II complex by ligand-binding to VDR has been shown to enhance the transcription of target genes.

Unexpectedly, we did not identify several well-known nuclear VDR-binding partners, including RXR (25). One reason could be that the introduction of the TAP-tag complex to the $C$-terminal end of the VDR protein may have prevented binding of RXR and other classical VDR partners to this nuclear receptor.

As published previously, the 427 amino acid VDR has various characteristics, with the two major functional units being the $N$-terminal zinc finger DNA binding domain, and the $C$-terminal ligand binding domain domains (26). The $\mathrm{X}$ ray crystallographic structure of the VDR including its ligand binding domain has been characterized before (27) with the $12 \alpha$-helical sandwich-like structure containing VDR subunits for heterodimerization with RXR (helices H7, H9 and H10. etc.), as well as for transactivation via binding of NCoAs. It has been reported that VDR-NCoAs interfaces correspond to helices $\mathrm{H} 3$ and $\mathrm{H} 12$ (the latter representing the activation function-2 domain), and an area immediately $N$ terminal of the zinc fingers (residues 18-22). Binding of human VDR to basal transcription factors such as transcription factor II B (TFIIB) (near the N-terminus of VDR), as well as with transcriptional corepressors such as the hairless $(\mathrm{Hr})$ gene product, which associates with the VDR hinge and H3, have also been shown before (26).

Recently, we had presented data suggesting that VDR interacts specifically and functionally with Mouse double 
a

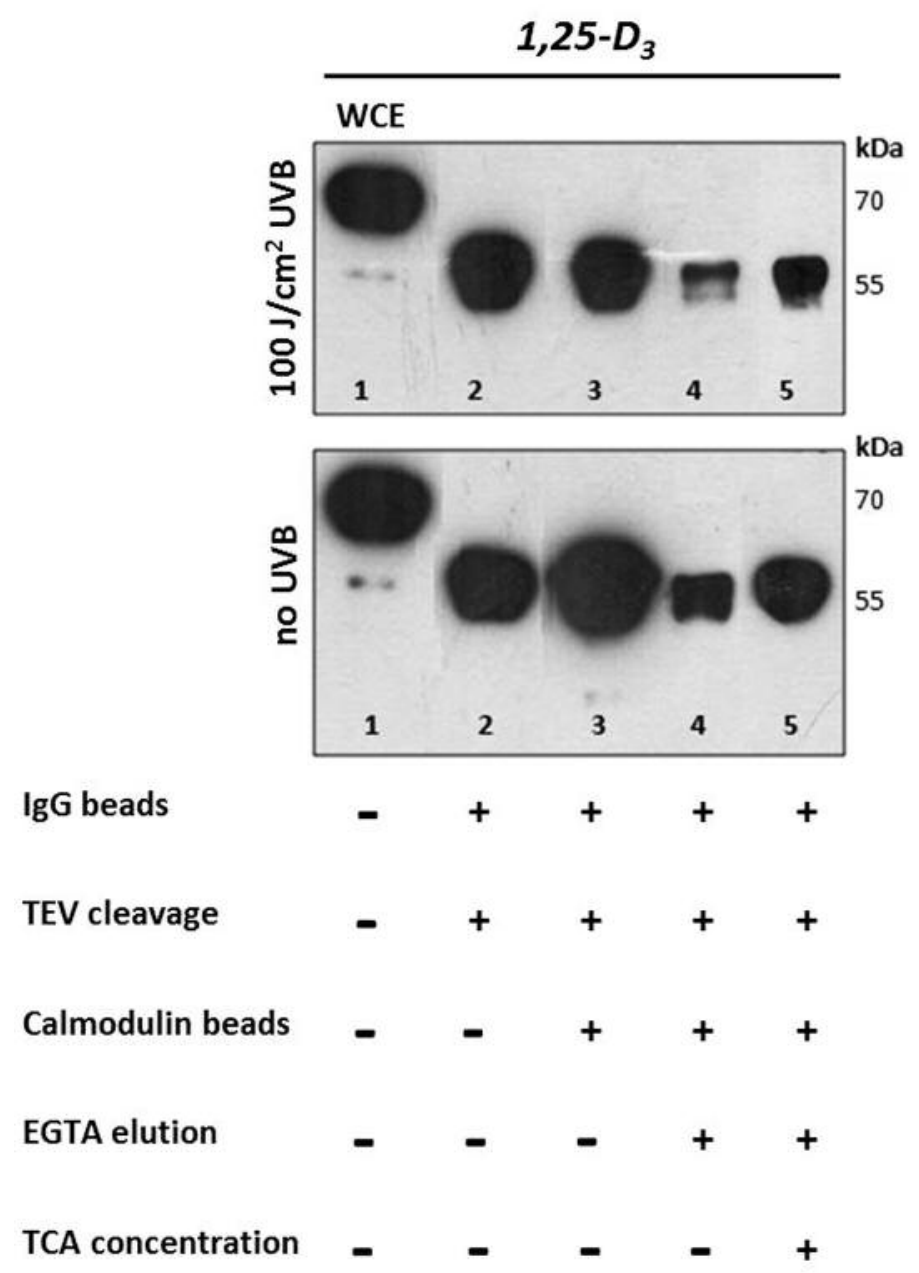

b

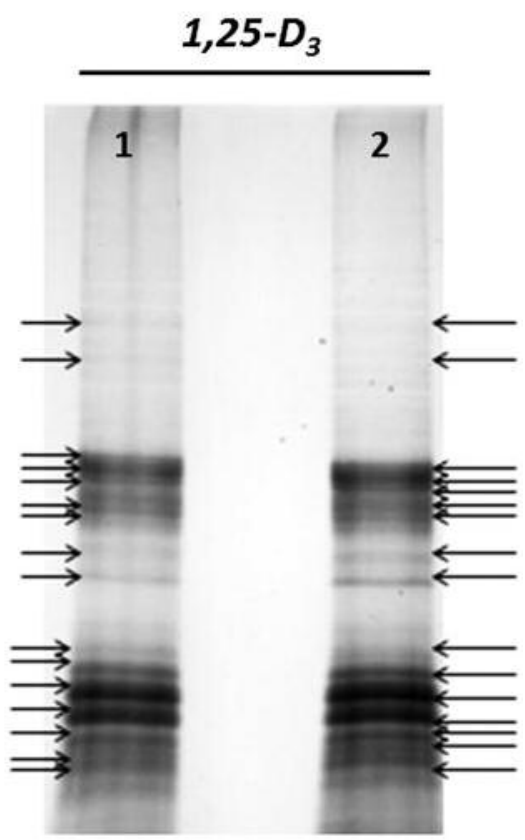

UVB

Figure 3. Vitamin D receptor (VDR) enrichment and visualization of VDR-interacting proteins. a: Step-by-step analysis of the tandem affinity purification (TAP)-VDR purification using TAP. HEK 293 T cells were transfected with pURB C Term TAP tag VDR-containing cDNA or pURB C Term TAP tag as control (data not shown). Twenty hours after transfection, HEK 293 T cells were incubated with 100 nM 1,25-dihydroxyvitamin $D_{3}$ $\left(1,25-D_{3}\right)$ following irradiation of $100 \mathrm{~J} / \mathrm{cm}^{2}$ UVB or mock irradiation (no UVB). After 4 hours, HEK $293 T$ cells were harvested and TAP-VDR was purified with the TAP strategy. A fraction of each eluate of the several steps of the TAP procedure was collected and subjected to sodium dodecyl sulfate polyacrylamide gel electrophoresis (SDS-PAGE), followed by western blot analysis with antibody directed against VDR (9A7). WCE: Whole cell extract. b: Visualization of VDR-interacting proteins via silver staining. TAP-isolated and trichloroacetic acid (TCA)-concentrated extracts from 1,25-D -treated and UVB-irradiated/non-irradiated HEK 293 T cells were size-separated via SDS-PAGE. VDR-interacting proteins were visualized using FireSilver StainingKit (Proteome Factory AG). Arrows indicate protein bands which were cut out and subsequently analyzed by nano high-performance liquid chromatography-electrospray ionization tandem mass spectrometric analysis.

minute 2 homolog (MDM2) (28). However, we were not able to detect this interaction by TAP following nano-HPLCESI-MS/MS. This may be the result of MDM2 being expressed in only very small quantities in HEK 293T cells. Moreover, the introduction of the TAP construct to the $C$ terminal of VDR may have masked the binding site for MDM2. We recently showed that MDM2 is primarily in contact with VDR via its center and $C$-terminus (28).
A further interesting result of this pilot study was the identification of several VDR-binding proteins exclusively in UV-B-treated compared to untreated HEK 293T cells, e.g. mediator of RNA polymerase II, nuclease-sensitive element binding protein 1 and mitochondrially located HSP60 (Table I). These findings suggest a contribution of VDR to the cellular stress response that involves the mitochondria, and a putative cross-talk between vitamin $\mathrm{D}$ and heat-shock 


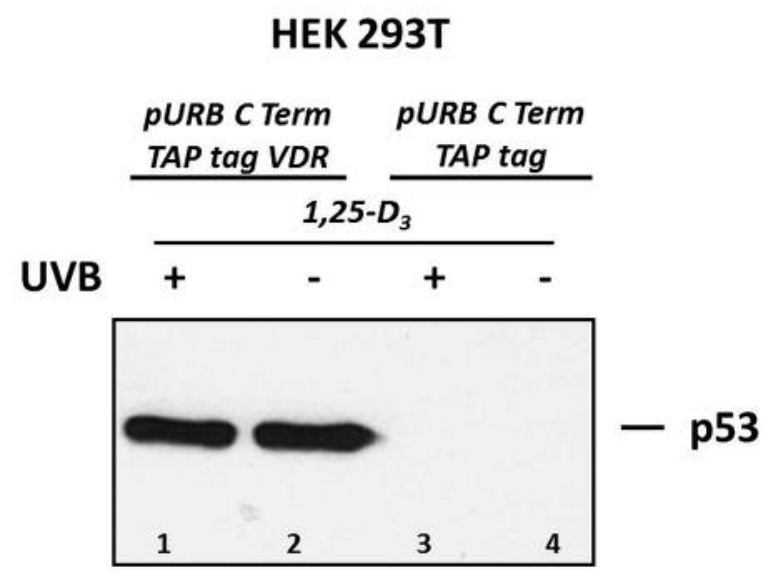

Figure 4. Vitamin D receptor (VDR) binds to p53. HEK 293 T cells were transfected with $p U R B$ C Term TAP tag VDR-containing $C D N A$ or pURB $C$ Term TAP tag as control (data not shown). Twenty hours after transfection, HEK $293 \mathrm{~T}$ cells were incubated with $100 \mathrm{nM}$ 1,25dihydroxyvitamin $D_{3}\left(1,25-D_{3}\right)$ following irradiation of $100 \mathrm{~J} / \mathrm{cm}^{2} \mathrm{UVB}$ or mock irradiation. Four hours later, HEK 2937 cells were harvested and TAP-VDR was purified with the TAP strategy. A fraction of the eluate after EGTA elution was subjected to sodium dodecyl sulfate polyacrylamide gel electrophoresis (SDS-PAGE), followed by western blot analysis with antibody directed against $p 53$.

signaling pathways. HSP60 is involved in the prevention of heat-induced protein damage and the transportation and refolding of cellular proteins from the cytoplasm into the mitochondrial matrix $(29 ; 30)$. Additionally, studies have indicated a role of HSP60 in several disorders where the relevance of the vitamin $\mathrm{D}$ endocrine system has been discussed, including stress response, diabetes, cancer and certain types of immunological disorders (30-33). It can be speculated that HSP60 may be involved in the putative transportation of VDR from cytoplasm to mitochondrial matrix. However, the association between HSP60 and VDR needs to be confirmed by western blot analysis.

In addition to HSP60, several different types of mitochondrial proteins were also identified as VDR-binding partners, including ADP/ATP translocase 2 and 3, which both catalyze the exchange of cytoplasmic ADP with mitochondrial ATP across the mitochondrial inner membrane, as well as mitochondrial ribosomal protein MRPS27, which is involved in mitochondrial translation. The biological relevance of these associations is currently unknown and should be investigated in further studies.

Our findings link VDR to ribosomes (Table I), the organelles that catalyze protein synthesis. In general, they contain a small 40S subunit and a large 60S subunit which, in total, consist of four RNA species and approximately 80 structurally distinct proteins. The MS analysis revealed that VDR binds to the ribosomal proteins S2, S3, S4, S6, S22, L3,
L5 and L7 among others. The interaction of VDR with ribosomal protein $\mathrm{L} 7$, which is a component of the ribosomal $60 \mathrm{~S}$ subunit, has been previously been shown. L7, which is located in the cytoplasm, specifically associates with VDR in the presence of vitamin D and is a co-regulator of VDR-RXRmediated transactivation of genes modifying transcriptional activity by interrupting binding of the receptors to genomic enhancer elements (34). The molecular biological evidence of these interactions remains to be provided.

Although we did not detect several classical VDR-binding partners, including RXR, we conclude that our approach represents a promising tool for identifying VDR-interacting proteins. However, the physiological relevance of our findings needs to be investigated in future experiments. Besides other limitations, our method is unable to discriminate whether identified proteins are bound to VDR directly or via other bridging proteins. Moreover, we cannot exclude that we may have overlooked other important VDR-binding partners. However, this should not question the relevance of the VDR interaction partners that we have identified.

Considering the high physiological relevance of p53 and other proteins that we identified as new VDR-binding partners, our findings may point to previously unidentified functions and regulations of VDR that deserve systematic analysis in future studies.

\section{References}

1 Holick MF: Vitamin D deficiency. N Engl J Med 357(3): 266281, 2007.

2 Carlberg C: Genome-wide (over)view on the actions of vitamin D. Front Physiol 5: 167, 2014.

3 Haussler MR, Whitfield GK, Kaneko I, Haussler CA, Hsieh D, Hsieh JC and Jurutka PW: Molecular mechanisms of vitamin D action. Calcif Tissue Int 92(2): 77-98, 2013.

4 Sequeira VB, Rybchyn MS, Tongkao-On W and GordonThomson C, Malloy PJ, Nemere I, Norman AW, Reeve VE, Halliday GM, Feldman D and Mason RS: The role of the vitamin D receptor and ERp57 in photoprotection by $1 \alpha, 25$ dihydroxyvitamin $\mathrm{D}_{3}$. Mol Endocrinol 26(4): 574-582, 2012.

5 Rigaut G, Shevchenko A, Rutz B, Wilm M, Mann M and Séraphin B: A generic protein purification method for protein complex characterization and proteome exploration. Nat Biotechnol 17(10): 1030-1032, 1999.

6 Hublitz P, Kunowska N, Mayer UP, Müller JM, Heyne K, Yin N, Fritzsche C, Poli C, Miguet L, Schupp IW, van Grunsven LA, Potiers N, van Dorsselaer A, Metzger E, Roemer K and Schüle R: NIR is a novel INHAT repressor that modulates the transcriptional activity of p53. Genes Dev 19(23): 2912-2924, 2005.

7 Shevchenko A, Tomas H, Havlis J, Olsen JV and Mann M: Ingel digestion for mass spectrometric characterization of proteins and proteomes. Nat Protoc 1(6): 2856-2860, 2006.

8 Perkins DN, Pappin DJ, Creasy DM and Cottrell JS: Probabilitybased protein identification by searching sequence databases using mass spectrometry data. Electrophoresis 20(18): 35513567,1999 . 
9 Fellahi S, Chibani A, Feuk-Lagerstedt E and Taherzadeh MJ: Identification of two new keratinolytic proteases from a Bacillus pumilus strain using protein analysis and gene sequencing. AMB Express 6(1): 42, 2016.

10 Higashitsuji $\mathrm{H}$, Higashitsuji $\mathrm{H}$, Masuda T, Liu Y, Itoh K and Fujita J: Enhanced deacetylation of p53 by the anti-apoptotic protein $\mathrm{HSCO}$ in association with histone deacetylase 1. J Biol Chem 282(18): 13716-13725, 2007.

11 de Gruijl FR, van Kranen HJ and Mullenders LH: UV-induced DNA damage, repair, mutations and oncogenic pathways in skin cancer. J Photochem Photobiol B 63(1-3): 19-27, 2001.

12 Ziegler A, Jonason AS, Leffell DJ, Simon JA, Sharma HW, Kimmelman J, Remington L, Jacks T and Brash DE: Sunburn and p53 in the onset of skin cancer. Nature 372(6508): 773-776, 1994.

13 Latonen L and Laiho M: Cellular UV damage responses functions of tumor suppressor p53. Biochim Biophys Acta 1755(2): 71-89, 2005.

14 Bikle DD: Vitamin D receptor, a tumor suppressor in skin. Can J Physiol Pharmacol 93(5): 349-354, 2015.

15 Benjamin CL, Ullrich SE, Kripke ML and Ananthaswamy HN: p53 tumor suppressor gene: a critical molecular target for UV induction and prevention of skin cancer. Photochem Photobiol 84(1): 55-62, 2008.

16 Stambolsky P, Tabach Y, Fontemaggi G, Weisz L, Maor-Aloni R and Siegfried Z, Shiff I, Kogan I, Shay M, Kalo E, Blandino G, Simon I, Oren $M$ and Rotter V: Modulation of the vitamin $\mathrm{D}_{3}$ response by cancer-associated mutant p53. Cancer Cell 17(3): 273-285, 2010.

17 Heyne K, Willnecker V, Schneider J, Conrad M, Raulf N, Schüle $\mathrm{R}$ and Roemer K: NIR, an inhibitor of histone acetyltransferases, regulates transcription factor TAp63 and is controlled by the cell cycle. Nucleic Acids Res 38(10): 3159-3171, 2010.

18 Heyne K, Förster J, Schüle R and Roemer K: Transcriptional repressor NIR interacts with the p53-inhibiting ubiquitin ligase MDM2. Nucleic Acids Res 42(6): 3565-3579, 2014.

19 Okamoto T, Izumi H, Imamura T, Takano H, Ise T, Uchiumi T, Kuwano $\mathrm{M}$ and Kohno K: Direct interaction of $\mathrm{p} 53$ with the $\mathrm{Y}$ box binding protein, YB-1: a mechanism for regulation of human gene expression. Oncogene 19(54): 6194-6202, 2000.

20 Galbán S, Martindale JL, Mazan-Mamczarz K, López de Silanes I, Fan J, Wang W, Decker J and Gorospe M: Influence of the RNA-binding protein HuR in pVHL-regulated p53 expression in renal carcinoma cells. Mol Cell Biol 23(20): 7083-7095, 2003.

21 Tong $X$ and Pelling JC: Enhancement of p53 expression in keratinocytes by the bioflavonoid apigenin is associated with RNA-binding protein HuR. Mol Carcinog 48(2): 118-129, 2009.

22 Ahuja D, Goyal A and Ray PS: Interplay between RNA-binding protein HuR and microRNA-125b regulates p53 mRNA translation in response to genotoxic stress. RNA Biol 13(11): 1152-1165, 2016.
23 Colombo E, Marine JC, Danovi D, Falini B and Pelicci PG: Nucleophosmin regulates the stability and transcriptional activity of p53. Nat Cell Biol 4(7): 529-533, 2002.

24 Rachez C, Lemon BD, Suldan Z, Bromleigh V, Gamble M, Näär AM, Erdjument-Bromage $\mathrm{H}$ and Tempst $\mathrm{P}$ and Freedman LP: Ligand-dependent transcription activation by nuclear receptors requires the DRIP complex. Nature 398(6730): 824-828, 1999.

25 Yu VC, Delsert C, Andersen B, Holloway JM, Devary OV, Näär AM, Kim SY, Boutin JM, Glass CK and Rosenfeld MG: RXR beta: a coregulator that enhances binding of retinoic acid, thyroid hormone, and vitamin $\mathrm{D}$ receptors to their cognate response elements. Cell 67(6): 1251-1266, 1991.

26 Haussler MR, Haussler CA, Bartik L, Whitfield GK, Hsieh JC, Slater S and Jurutka PW: Vitamin D receptor: molecular signaling and actions of nutritional ligands in disease prevention. Nutr Rev 66(10 Suppl 2): S98-112, 2008.

27 Rochel N, Wurtz JM, Mitschler A, Klaholz B and Moras D: The crystal structure of the nuclear receptor for vitamin $\mathrm{D}$ bound to its natural ligand. Mol Cell 5: 173-179, 2000.

28 Heyne K, Heil TC, Bette B, Reichrath J and Roemer K: MDM2 binds and inhibits vitamin D receptor. Cell Cycle 14(13): 20032010, 2015.

29 Koll H, Guiard B, Rassow J, Ostermann J, Horwich AL, Neupert W and Hartl FU: Antifolding activity of hsp60 couples protein import into the mitochondrial matrix with export to the intermembrane space. Cell 68(6): 1163-1175, 1992.

$30 \mathrm{Wu}$ J, Liu T, Rios Z, Mei Q, Lin X and Cao S: Heat-shock proteins and cancer. Trends Pharmacol Sci 38(3): 226-256, 2017.

31 Shamovsky I and Nudler E: New insights into the mechanism of heat-shock response activation. Cell Mol Life Sci 65(6): 855861, 2008.

32 Juwono J and Martinus RD: Does Hsp60 provide a link between mitochondrial stress and inflammation in diabetes mellitus? J Diabetes Res 2016: 8017571, 2016.

33 Quintana FJ and Cohen IR: The HSP60 immune system network. Trends Immunol 32(2): 89-95, 2011.

34 Berghöfer-Hochheimer Y and Zurek C, Wölfl S, Hemmerich P and Munder T: L7 protein is a coregulator of vitamin D receptorretinoid $\mathrm{X}$ receptor-mediated transactivation. J Cell Biochem 69(1): 1-12, 1998. 